\title{
EVALUATING SUBSCRIBERS PREFERENCE FOR SERVICE ATTRIBUTES OF MOBILE TELECOMMUNICATION IN NIGERIA USING ANALYTIC HIERARCHY PROCESS (AHP)
}

\author{
Emmanuel Olateju Oyatoye \\ Department of Business Administration, \\ University of Lagos, Nigeria. \\ E-mail: eoyatoye@unilag.edu.ng \\ Sulaimon Olanrewaju Adebiyi \\ Department of Business Administration, \\ Federal University of Agriculture Abeokuta (FUNAAB) \\ E-mail: lanre18april@gmail.com \\ Bilqis Bolanle Amole \\ Distance Learning Institute, \\ Department of Business Administration, \\ University of Lagos, Nigeria. \\ E-mail:amolebb@yahoo.com
}

\begin{abstract}
Policy and strategies in the growing Nigeria telecommunication industry can only have significant impact if it is substantially driven by research on what subscribers preferred and why they do? Thus the need for operations research model (AHP) to evaluate customer preference of their mobile telecommunication attributes so as to direct policy and strategies at what is/are important to subscribers whom were the essence of business activities. The paper built hierarchical model for choice/determinant of subscribers' preference for mobile telecommunication attributes in Nigeria as the goal, using seven main attributes as the criteria for evaluation, while the four main players in the GSM market (MTN, Airtel, Glo and Etisalat) are the alternatives. An AHP based questionnaires was administered and distributed among student of tertiary institutions in Lagos. Out of the four hundred questionnaires distributed, only three hundred and eighty six were duly filled, returned and found suitable for the analysis. The data was analyzed, considering the set of evaluation criteria (service attributes), and a set of alternative (network providers) scenarios among which the best decision is to be made. We generated a weight for each evaluation criterion and scenario according to the information provided by the decision makers (stakeholders). AHP was used to combine the objective and scenario evaluations to determine the ranking for scenarios. The result reveals that an average student preferred network providers with low rates (affordable) follow by quality of connections and reliable data plan for internet service. The priority was done for the criteria to direct strategic decisions in the telecommunication industry towards meeting subscribers' needs. Coverage was not given significant priority as the respondents assumed that all providers have similar coverage. This result of this study will assist at improving the quality of decision making of stakeholders.
\end{abstract}

Keywords: AHP, subscribers, preference, service attributes', telecommunication

\section{Introduction}

Thirteen years into the introduction of Global System for Mobile communication (GSM) in Nigeria, there is an increasing need for mobile phone services by an average Nigerian, unlike when it was introduced. Besides, SIMs now goes almost for free to subscribers/customers as there is no disparity 
in the price it is sold to high, medium or low profile citizen as it was done when it was launched in 2001.

Subscribers who have an increasing need for the use of mobile telecommunication attributes, are faced with a great deal of complexity not only in deciding which of the network providers should they settle with when the market has implemented mobile number portability (MNP) which accorded subscribers the opportunity of retaining their known and spread number rather than combining multiple SIMs, but which of the network providers is best suited to meet their economic, social and psychological needs.

The name of AHP explains its application logic (Silva, Alver, and Marins, 2009). Analytic: It assists in the measurement and synthesization of a series of factors involved in complex decisions; Hierarchy: Hierarchy is the adaptable way of finite intelligence to assume a complex situation; Process: A process is a series of actions, alterations or functions that leads to an end or result. The continuous marketing efforts of network providers in Nigeria as well as the perceived ineffectiveness of the regulatory authority - National Communication Commission(NCC) in the telecommunication sector has made this study to quest for evaluating subscriber preferences for the service attributes using AHP, in which the result will be beneficial to all the stakeholders, as the subscribers will be provided with a rational way for decision making that requires comparisons, priority and tradeoffs through the powerful multicriteria tool for analysis like AHP, the operator will understand what is important to subscribers among the criteria and in what order, so as to direct marketing effort/activities as well as strategies to enhance customer satisfaction when the need is met. Also, the regulator (NCC) will benefit by understanding the needs and complaints of subscribers so as to balance the interest in their policies and also to assess how effective subscribers perceiver the regulators.

This study is very important for the policy makers, subscribers, telecom operators and growth of Nigeria telecommunication industry as organisations in $21^{\text {st }}$ century can only survive the turbulent business environment when the needs and wants of the consumers/subscribers were identified, anticipating for the changes of their demands and satisfying these profitably. Thus, the study helps at evaluating the preferences of subscribers of the mobile services attribute in Nigeria, especially in relation to their day-to-day experiences while using GSM for communication which, also serve as the life blood of an average man and also enhances the development of other sector in any economy.

\section{Conceptual model for the study}

In this study, the mobile network attributes were extended based on literature and a preliminary interview granted some subscribers to seek for proper grouping of attributes identified from the literatures and use only those that subscribers are more concerned with. These include quality of calls, tariff, coverage, promotion, message delivery and complaint management. An average subscriber needs to be satisfied with all these attributes to a reasonable extent in order for him/her to continue to patronize the network providers, since the MNP allows him/her switched and still maintain the known number. Besides, it is only when the service providers knows how much value does the subscribers placed on the attributes comparatively that effective marketing strategies could be formulated to keep the profitable customers and persuade/encourage/enjoys potential subscribers to join their network.

AHP methodology involves decomposing of the decision problem into a set of variables that are organized into a hierarchy and enables decision makers compare and make choices among a number of alternatives. It allows for criteria priorities and making a series of tradeoffs among the criteria in relation to goals and as well as the alternatives. To adapt the AHP to this study required identification of the objective, the criteria. The AHP model adopts the use of diagram in form of hierarchy to model real-life situations (Saaty, 1980). The four levels of the model for this study were as follows; 
In this paper, convenient random sampling method was used to select four hundred subscribers of mobile networks providers whom filled the AHP based questionnaires while three hundred and eighty six filled appropriately and returned were evaluated. The sample was drawn to include subscribers of the four active mobile telecommunication services provider in Nigeria, these are MTN, Aitel, Glo and Etisalat customers/subscribers, whom filled the AHP based questionnaire on their experiences with network service providers of the attributes listed for comparisons in relation to the goal and alternatives. The questionnaires were distributed to people on campuses of the three higher institutions of learning (University of Lagos, Akoka, Lagos. Nigeria (UNILAG); Yaba College of Technology, Yaba Lagos (YABATECH); Federal College of Education Technical, Akoka. Lagos. Nigeria (FCETECH)), that were ready to participate in the survey. This comprises of student, staff (teaching and non-teaching), and visitors to the campuses, as well as the business people who can read to understand and answer the questions. The strategy used for prompt response was to meet people in places where they can give some time for filling the questionnaires, places like classroom for student after lectures, offices of lecturers and non-teaching staff, canteen/cafeteria, relaxation centers to mention a few. The data retrieved were analyzed using the IBM SPSS version 20 and Expert Choice 2000 software.

\section{REFERENCES}

Crawford, G., Williams, C., (1985). A note on the analysis of subjective judgment matrices. Journal of Mathematical Psychology, 29, 387-405.

Keeny, R.L. and Raiffa, H (1976). Decisions with Multiple objectives, Wiley, New York.

Oyatoye E.O, Adebiyi S.O and B. B, Amole (2013a). An empirical study on consumers preference for mobile telecommunication attributes in Nigeria. British Journal of Economics, Management \& Trade, 3(4): 419-428.

Oyatoye E.O, Adebiyi S.O and B. B, Amole (2013b). An application of conjoint analysis to consumer preference for beverage products in Nigeria. ACTA UNIVERSITATIS DANUBIUS, OECONOMICA, 9(6), 43-56.

Saaty, T.L., (1977). A scaling method for priorities in hierarchical structures. Journal of Mathematical Psychology, 15, 234-281.

Saaty, T.L. (1980). Analytical Hierarchy Process Planning, Priority Setting, Resource Allocation. McGraw-Hill, New York.

Saaty, T. L. (1990). An exposition of the AHP in reply to the paper - remarks on the analytic hierarchy process. Management Science, 36(3), 259-268.

Saaty, T.L. (2008). Relative measurement and its generalization in decision making why pairwise comparisons are central in mathematics for the measurement of intangible factors; the analytic hierarchy/network process, RACSAM., 102(2), 251-318.

Sato, Y., (2001). The impact on scaling on the pair-wise comparison of the analytic hierarchy process. The Proceeding on the Sixth International Symposium on the Analytic Hierarchy Process, $421-430$.

Silva, H.A., Alver, L.H.D. and Marins, F.A.S. (2009). Using AHP to evaluate the performance of the quality, environment, occupational health and safety management systems, Proceedings of the 10th International Symposium on the Analytic Hierarchy/Network Process Multi-criteria Decision Making, July 29 - August 1 2009, University of Pittsburgh, Pittsburgh, Pennsylvania, USA. 
Vargas, L.G., (1990). An overview of the analytic hierarchy process and its applications. European Journal of Operational Research, 48, 2-8.

Yoon, K.P. and Hwang C.L. (1995). Multiple Attribute Decision Making - An Introduction, Sage Publication, California. 